\title{
PANEURHYTHMY EXERCISES FOR DEVELOPING PARTNERSHIP AND SOCIAL SKILLS
}

\author{
Ludmila Chervencova \\ National Sports Academy "Vassil Levski”, Sofia, Bulgaria \\ Address for correspondence: \\ Ludmila Chervencova \\ NSA "Vassil Levski", Faculty of Public Health, Health Care and Tourism \\ Sofia, Bulgaria, 1000, 1 Gurguliat str. \\ E-mail: I.chervenkova@gmail.com
}

\begin{abstract}
Ahstract Paneurhythmy is a group psycho-physical practice created in Europe, involving marked social interaction. The purpose of this paper is to provide information about Paneurhythmy, and to discuss its potential as a means of development of partnership and social skills.

This article offers a brief introduction into Paneurhythmy. The basic characteristics of Paneurhythmy practices providing appropriate conditions for the improvement of partnership skills are formulated and explained. By means of analysis, discussion and examples, it is shown how Paneurhythmy for beginners and its further practice can develop skills for successful partnership with children and adults. The existent empirical and theoretical studies on the subject to date have been specified, confirming the cultivation of partnership and social skills through Paneurhythmy.

Paneurhythmy has an extremely big potential for the development of partnership skills and for the improvement of social functioning. In this respect, the most important characteristics of Paneurhythmy are the following: group practice in pairs, an appropriate aim of the practice, the right music, common rhythm and synchronization of movements, specific distances between participants, typical characteristics and expressiveness of participants' movements, Paneurhythmy philosophy, sharing space, suitable lyrics of Paneurhythmy songs, figures for the arrangement of participants, acting social roles and broadening the range of awareness. Paneurhythmy is a widely-accessible new instrument for personal and social development. This is confirmed by the existent scientific studies, revealing that, with children and adults, both initial training and further practising Paneurhythmy leads to the improvement of interpersonal relations and social skills.
\end{abstract}

Key WOrls outdoor exercise, learning, partnership, social skills

\section{Introduction}

Regardless of the fast development of technologies enhancing the exchange of information between contemporary generations, people nowadays suffer from a number of problems related to deficiencies in communication and social contacts. These deficiencies restrict their abilities for social realization and affect their health status, defined as the state of complete physical, mental and social well-being (WHO Constitution). The influence of positive social relations on human health has already been proven theoretically and confirmed in 
practice (Cohen, 2004; Umberson, Karas Montez, 2010). Research in social epidemiology uncover that the absence of positive social relationships is a significant risk factor for morbidity and mortality (Cacioppo, Cacioppo, 2014).

Prosocial behavior is voluntary, intentional action that benefits others. It finds expression in actions such as helping, sharing, cooperation and caring (Grusec, Davidov, Lundell, 2002). Prosocial behavior seems to be a key aspect of social competence and it has been positively associated with socioemotional (social competence, empathy-related responding) and sociocognitive outcomes in youth, and negatively associated with delinquency and aggression (Malti, Perren, 2011; Morris, Eisenberg, Houltberg, 2011).

Social skills and social understanding are substantial for individual psychological well-being and peer group adjustment (Smith, Hart, 2002). There are still needs for increasing the number of effective means that help children form and improve friendships (Ladd, Buhs, Troop, 2002). There are different ways to develop successful partnership and social skills, but their cultivation through practical activities is among the most successful. Motor practices, performed in a variety of open geometrical figures by large groups of varying sizes, could be not only a big challenge for partnership and social skills, but also an appropriate environment and important stimulus for their development. This article for the first time presents and analyses the potential of Paneurhythmy as unique contemporary system of psycho-physical exercises for the effective development of social skills with people of all ages.

\section{What is Paneurhythmy}

Paneurhythmy is a unique psycho-physical activity consisting of exercises performed to music outdoors, in pairs and in groups (Figures 1 and 2). It has three parts, comprising 30 exercises, performed with small pauses between them and two longer breaks/pauses for rearrangement. The duration of one complete performance with pauses is about 70 minutes. In the course of the year it is practiced daily in the open air for about 6 months, when nature is in its period of flowering and growth: from March 22 to September 22 (for the northern hemisphere of the Earth). For the other 6 months, classes in Paneurhythmy for beginners are usually organized. The intensity of exercises in Paneurhythmy for healthy physically active people is usually low to average. With people of lower physical capacity or illness, the relative intensity of the exercises could be greater (Beinsa Douno, 1938; Beinsa Douno, 2004; Chervencova, Ishev, 2015).

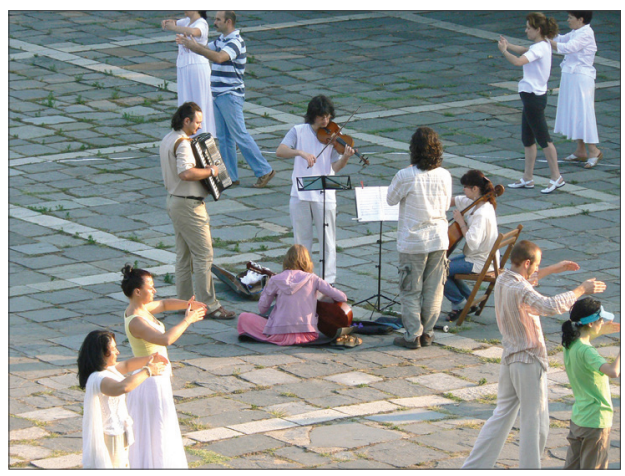

Figure 1. Paneurhythmy in Plovdiv, Bulgaria

Source: Photo by Zhsivko Stoilov. 
On a global scale, Paneurhythmy has no analogy - it is a unique Bulgarian and European kind of physical activity. It combines the positive influence of a number of powerful factors on the participants, such as motion, music, poetry, words, songs, breathing, concentration of thought, abstract thinking, positive emtions, light, fresh air, connection with nature and social contacts. Since Paneurhythmy involves a great variety of arts - movementbased creative expression, music, poetry, speech and theatrical elements (there is a story line, tells stories through movement), it is rightfully also considered as an art therapy. Paneurhythmy is very attractive as it is easily accessible, very pleasant, and in accordance with the latest interests and trends of development of the modern world. In less than 100 years since the creation of Paneurhythmy, it has won legions of fans from many countries around the world (Deunov, 2015; Naydenova, 2003; Chervencova, 2013).

Paneurhythmy was created in Bulgaria in the first half of the previous century by the Bulgarian theologian, philosopher and musician Peter Deunov, who was recognized by Bulgarians and foreigners as their devoted spiritual teacher (Chervencova, 2013; Bachev, 2017). According to him, Paneurhythmy aims to improve and sustain physical health in all its aspects - physical, psychological and social, and it is also an effective means of harmonizing the thoughts, feelings and actions of its participants and of helping the progress of man and society (Beinsa Douno, 1938). Practising Paneurhythmy could be a means of education and self-education for the acquisition and development of important qualities for modern man; moral strength, will power and social skills (Boycheva, Donevska, Vancheva, 2001; Anchev, 2003; Matanova, Yankova, 2007a, 2007b).

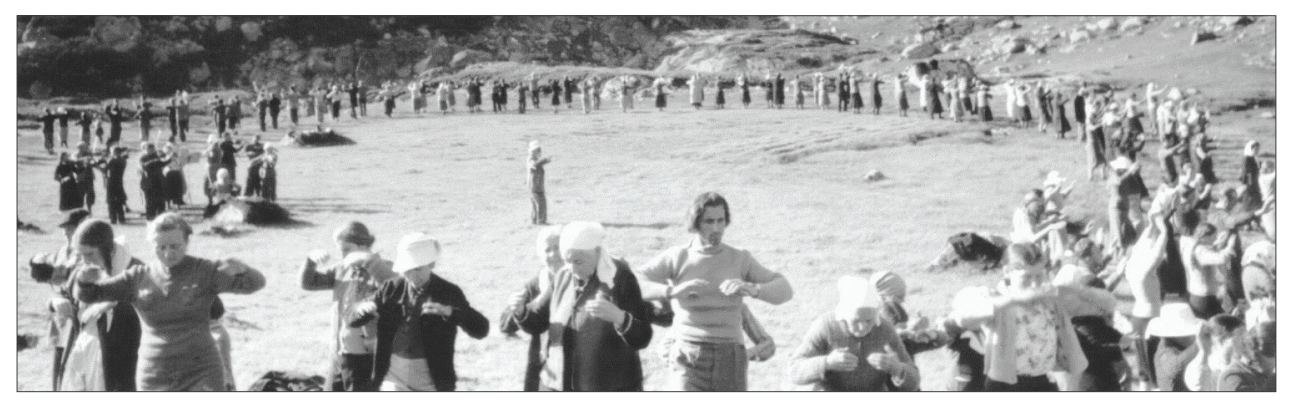

Figure 2. Paneurhythmy in Rila Mountain (before 1940)

Paneurhythmy was created to be a widely accessible means of sustaining human health and for the all-round development of people. The flowing and beautiful movements of Paneurhythmy, its musical variety and the contact with nature during the performances, are pleasant and attractive for children, adults and elderly people. Modern research on Paneurhythmy has revealed that both the beginner course and further practice of Paneurhythmy bring psychological and physical benefits. The following significant positive changes have been measured after 5-6 months of Paneurhythmy training (these were not observed in the control group): improved static balance; improved dynamic functional balance and general mobility; improved strength endurance of some muscle groups; decreased level of state anxiety, trait anxiety, perceived stress, negative emotions, aggression and depression; at the same time there are increased positive emotions, subjective happiness, self-esteem, hope, general self-efficacy, 
optimism, resilience, sense of coherence and life satisfaction; improved quality of life, increased general subjective health and working capacity (Chervencova, 2012, 2013).

Paneurhythmy contains non-traumatic strengthening and aerobic exercises that are good for maintaining flexibility. Paneurhythmy significantly improves balance in middle-aged people and is suitable for effective early prevention of falls in elderly people. It is extremely accessible regardless of financial condition or physical characteristics of the participants and can be performed by people aged from 5 to 95 (Figures 2 and 3). It does not require expensive equipment or facilities and it is also suitable for people with certain compensated chronic diseases (Chervencova, Ishev, 2015).

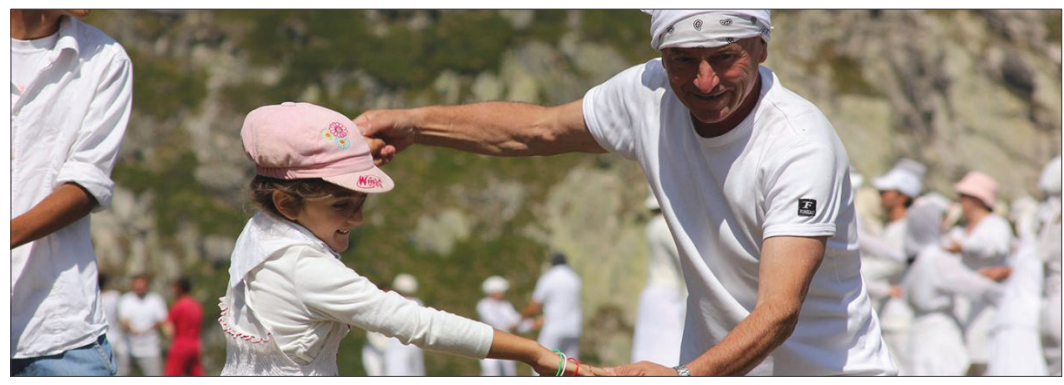

Figule 3. Paneurhythmy

Source: Photo by Zhsivko Stoilov.

The specific characteristics of Paneurhythmy and the positive results are shown in Table 1. Characteristics numbered 1 to 7 describe Paneurhythmy in general, while those numbered 8-11 are more closely related to developing partnership skills. Actually, all components of Paneurhythmy are created so that they enhance successful communication and the improvement of skills towards a creative partnership.

Table 1. Specific characteristics in the performance of Paneurhythmy exercises

\begin{tabular}{|c|c|}
\hline Specific characteristics & Results \\
\hline 1 & 2 \\
\hline 1. Relatively slow and always smooth movements & $\begin{array}{l}\text { Opportunity for conscious control of movements. Great accessibility with reference } \\
\text { to movement (accessible from the age of about } 5 \text { to } 95 \text { ) }\end{array}$ \\
\hline 2. Rhythmic performance & $\begin{array}{l}\text { Easier to learn. Develops a sense of rhythm. A sense of union through the performance } \\
\text { in the same rhythm }\end{array}$ \\
\hline 3. Specific gait (always stepping on toes first) & Decreased micro commotions while walking. Improved gait. Strengthened calf muscles \\
\hline 4. Music is a key element in the exercises & $\begin{array}{l}\text { The practice is more pleasant. Music has an emotional and an aesthetic influence. Music } \\
\text { therapy }\end{array}$ \\
\hline 5. Poetic text and basic philosophical idea for each exercise & $\begin{array}{l}\text { Influence through the spoken word (the song lyrics, the names of exercises). Adequate } \\
\text { thought stimulation and connecting the activity with noble ideas. }\end{array}$ \\
\hline $\begin{array}{l}\text { 6. A requirement that participant movements should be } \\
\text { meaningful and beautiful }\end{array}$ & $\begin{array}{l}\text { Greater involvement of thought. Creativity - participants seek to discover those beautiful } \\
\text { movements }\end{array}$ \\
\hline 7. Performing in the open air close to beautiful nature & $\begin{array}{l}\text { Healing effect of natural factors (sun, wind, water, cleanliness, ionization of the air, } \\
\text { and etc.). Stress relieving and aesthetic influence of the natural environment }\end{array}$ \\
\hline
\end{tabular}




\begin{tabular}{|c|c|}
\hline 1 & 2 \\
\hline $\begin{array}{l}\text { 8. Geometry and coordination. The exercises are performed } \\
\text { in pairs and movements require time and/or space } \\
\text { coordination (with music, the partner in the pair, adjacent } \\
\text { pairs, other pairs, the performance of joint geometric } \\
\text { figures, outside natural objects) }\end{array}$ & $\begin{array}{l}\text { Conditions are provided for considerable and constant involvement of thought. } \\
\text { Development of intellectual skills (space orientation, improvement of concentration } \\
\text { of attention, abstract thinking, etc.). Attention span is improved naturally with increased } \\
\text { practice, and special skills of awareness to group activities are developed, on several } \\
\text { levels }\end{array}$ \\
\hline $\begin{array}{l}\text { 9. Group performance (approximate number of participants: } \\
\text { from } 10 \text { to } 500-1000 \text { and more) forming of geometric } \\
\text { figures in common }\end{array}$ & $\begin{array}{l}\text { Very good conditions for development of team-working skills in an informal environment. } \\
\text { Social contacts }\end{array}$ \\
\hline $\begin{array}{l}\text { 10. Performance in pairs which are organized in circles and/or } \\
\text { form many groups of } 10 \text { or } 12 \text { people, arranged in complex } \\
\text { regular geometric figures }\end{array}$ & $\begin{array}{l}\text { Higher requirements towards the coordination of individual and collective movements. } \\
\text { Great potential for improvement of concentration and the scope of attention. Forming } \\
\text { a sense of partnership. Forming an awareness of social roles }\end{array}$ \\
\hline $\begin{array}{l}\text { 11. Ideas and Philosophy. Each Paneurhythmy exercise } \\
\text { symbolizes a sublime idea implied in its name. } \\
\text { The arrangement of the participants and the directions } \\
\text { of their movements also have a symbolic meaning }\end{array}$ & $\begin{array}{l}\text { Development of abstract thinking. Development of attitudes that create and sustain } \\
\text { peaceful societies. Seeking correspondence between ideas, music and motion. A purely } \\
\text { mechanical execution of the exercises is avoided. There are conditions for the mind to be } \\
\text { active all the time }\end{array}$ \\
\hline
\end{tabular}

The author of Paneurhythmy received his education at the end of the XVIII century in Europe and America. Peter Deunov was familiar with the contemporary philosophy of his time and also with the philosophy of antiquity, along with the cultural and philosophical trends of development of the East and the West in general (Bachev, 2017). M. Bachev defines the teaching of P. Deunov as "representing the meeting between man and the source of life, wisdom and intellect, East and West, prophetic and philosophical, culture and nature" (Bachev, 2015, p. 37). According to David Lorimer, the teachings of P. Deunov are part of the "Western esoteric tradition, steeped as it was not only in Platonism but also the original spirit of Christianity" (Kraleva, 2001, p. 9).

Paneurhythmy appeared and developed as a system of exercises between 1932 and 1944 in the cultural environment of an ancient European and Christian country. At about the same time, in 1936, Carl Jung stated that he expected the appearance of a psycho-physical and spiritual practice in Europe, similar to yoga, originating from the Christian tradition and the Western cultural heritage (Jung, 2014). Paneurhythmy, even though quite different from yoga, has similar general characteristics: it is a psycho-physical practice, aimed at providing human health and development in all its aspects; it could be used as a practice for self-development; it has a profound philosophical basis; it has unique specific aspects and is an attractive means of sustaining good health and wellbeing of modern man. Consequently, Paneurhythmy may be called the Yoga of the West, developed on the basis of Christianity, the practice which Carl Jung expected to be created.

\section{Importance of the research}

Paneurhythmy still has not been studied enough scientifically. Over 100 research works on Paneurhythny have been published so far. Among them there is not even one work devoted on the profound, purposeful study of the multiaspectual potential of this practice in the field of communication. There are results from separate studies, pointing to the fact that Paneurhythmy can be very useful for the improvement of communication skills. Nevertheless, there is no basic analysis or general review of the studies on this topic, stating why and how Paneurhythmy in particular has the potential to improve social relations. That kind of analysis can be the necessary theoretical basis, showing the potential of Paneurhythmy to improve social relations, and providing a broad framework for future research in this direction. 
The objective of this article is to reveal the potentials of Paneurhythmy to stimulate partnership and social relations.

\section{Research methods}

1. A theoretical analysis of the specific characteristics of Paneurhythmy, enhancing the improvement of partnerships and social relationships. This article is aimed at a detailed and complete outline, based on theoretical analysis, of the components of Paneurhythmy, which have a positive influence on social relations and communication. The author's personal experience in practicing and teaching Paneurhythmy is the basis on which 11 characteristics of Paneurhythmy have been identified and stated here, helping to improve relationships and communication.

2. A review of current research of Paneurhythmy has been done in order to determine what is proven about its influence on the social sphere.

\section{Characteristics of Paneurhythmy developing partnership and groupwork skills}

\section{Group practice, performed in pairs}

The mere fact that Paneurhythmy is a group motor practice (Figure 4) with a variety of interactions between the participants during its performance is a condition for the development of partnership and social skills.

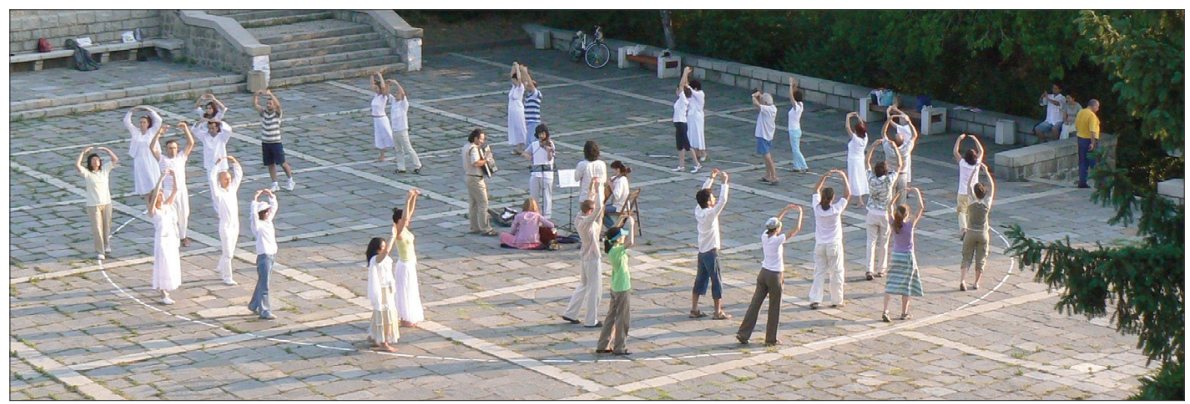

Figure 4. The first part of Paneurhythmy ("28 exercises"). Paneurhythmy in Plovdiv, Bulgaria Source: Photo by Zhsivko Stoilov.

\section{The aim of the practice}

Most importantly during the performance of Paneurhythmy is for the whole group to do the Paneurhythmy exercises beautifully and in harmony. Consequently, the aim of the practice is not to elect a winner, to compete or to dominate in competition, which could lead to contradictions. Paneurhythmy requires constructive cooperation, leading to the creation of harmony and beauty. So, each Paneurhythmy performance requires the right attitude in an effort to offer help and partnership. 


\section{Group rhythm and synchronization of movements}

According to J. Phillips-Silver, C. Athena, C. Aktipis and G. Bryant (2010), probably there is no other kind of human behavior uniting people as much as coordinated rhythmic movement. Grounded on a vast literary review on the subject, the authors point out that the human ability to follow the rhythm of another human or external stimulus is rooted in the physical, emotional and social aspects of the human experience, which are essentially connected with music and dance (Phillips-Silver et al., 2010). Performing all Paneurhythmy exercises, participants do many similar (actually almost similar or completely the same) synchronized rhythmic movements with their limbs. This circumstance increases their sense of union. Due to the fact that Paneurhythmy always presents a reasonably coordinated and rhythmic group movement, it has the power to unite its practitioners, helping them feel a sense of belonging to the group.

\section{Types of distances and movements in the pairs}

All movements which the participants perform with their limbs and body, are smooth and calm, they do not aggressively enter other people's personal space, which instills a peaceful atmosphere. The members of a pair are nearest to each other, at varying distances, but not less than an arm's length away from one another. According to the "body language" code accepted in our culture, such a distance is normally used in situations of common professional activities and friendly (but not intimate) relations, to express feelings of friendship and cooperation.
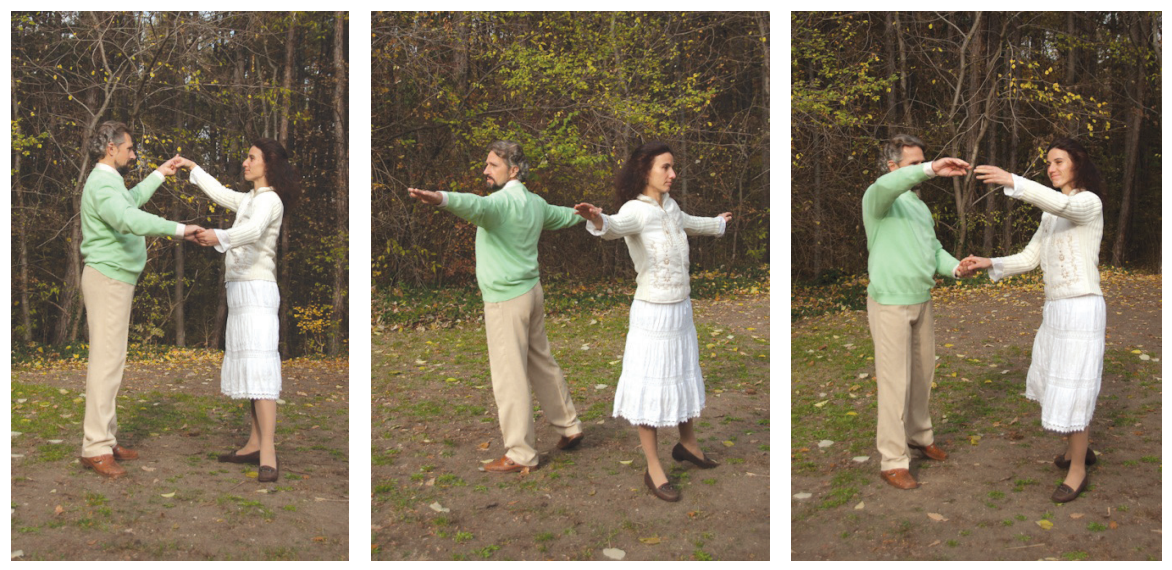

Figure 5. Moments of exercise no. 22 - "Acquaintance"

Source: Photos by Svetla Neykova.

At the beginning of Paneurhythmy, interaction between partners in each pair increases gradually - as if they are given time for internal harmonization before their physical contact. In the first exercises of Paneurhythmy, partners dance in synchrony, parallel to each other, later they exchange their places for the first time (in exercise no. 13 - "Weaving") and only in exercise no. 22 (Figure 5) do they hold hands from time to time, this also happens in some of the following exercises (exercises no. 22-24 and 26). The type of movements for each couple when holding 
hands shows friendly relations: all types of holds are palm to palm, they are performed smoothly and express introduction, exchange and mutual support (a wide hold with both hands, holding only the palms of the hands or holding the palm and then the top of the hand, and with more difficult balance exercises, holding the palm of the partner sometimes helps to keep their balance) (Figure 6).

From another aspect, holding hands in Paneurhythmy exercises almost always leads to a forward movement of both partners in the direction of the general movement in the circle. Since in most cultures and in Paneurhythmy itself, forward movement symbolizes evolution and progress, holding hands while moving forward is an expression of mutual support of the pair, aiming at the same goal of progress and development.

With reference to the meaning of the movements in Paneurhythmy, the level at which partners hold their hands symbolizes their sphere of partnership. For example, holding palm to palm (which is the only way of holding hands in Paneurhythmy), as well as positioning the hands held together above shoulder level, symbolizes communication with an exchange of thoughts. Hand movement at breast level, and holding palms at that level, symbolizes an exchange of feelings. According to those symbols, predominating hand movements in exercises, where partners hold their hands, show communication with an exchange of thoughts/ideas and feelings/emotions between partners.

The types of movements, the distance between the partners, holding hands in pairs while performing Paneurhythmy, all helps to create an atmosphere of friendly communication and support in the name of mutual progress.
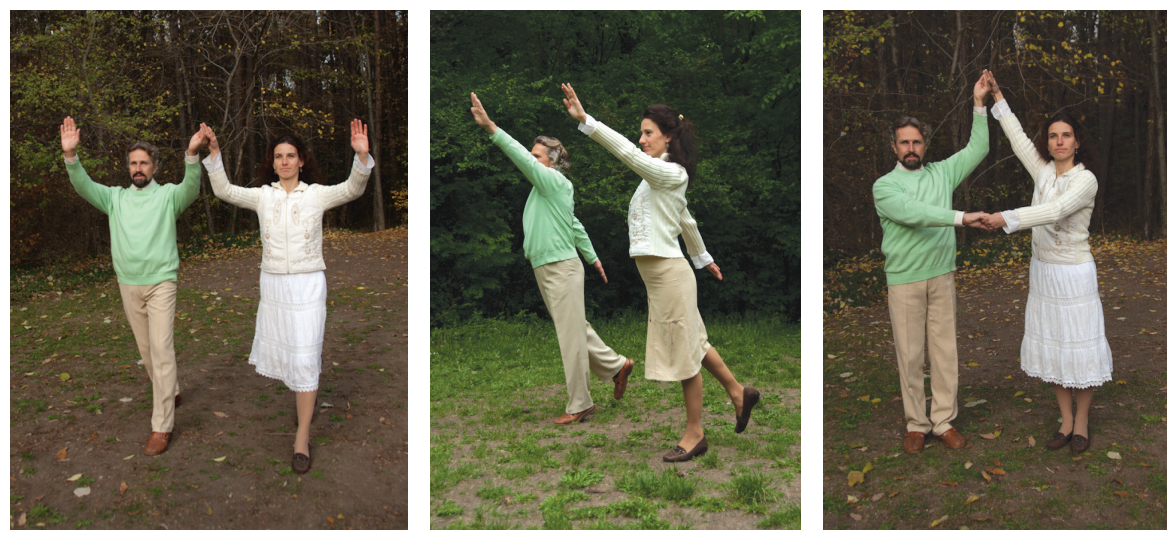

Figulu 6 . Moments of Paneurhythmy exercises

Source: Photos by Svetla Neykova.

\section{Sharing space}

A very important detail, through which Paneurhythmy stimulates the development of partnership skills, is the necessity while practicing to share the space (Figure 7). For example, while moving forward, partners in the pair try to do the exercises together, taking care to keep an adequate distance between each other, so that each has enough space to do the Paneurhythmy movements without obstructing the other. The same thing happens with the 
adjacent pairs from the moving circle formed by the whole group - they have to take care with the length of their strides and the distance from other pairs, their strides should be enough to maintain the required space to others. In the second and third part of Paneurhythmy, sharing space becomes much more complicated as there are many groups of 10, 12 and more people performing exercises with more complex geometric figures in the groups.

Thanks to the variety of ways to share space while performing Paneurhythmy, participants are taught to be careful about the need of space for others in a situation of creative partnership, while doing an activity together. We believe that everyone who practices Paneurhythmy long enough manages to develop the skills of sharing space with others due to this practice. This teaches awareness of, and respect for, providing space for others in common activities while performing Paneurhythmy. When the skills of providing space for all participants at the same time and in a fair way are developed through Paneurhythmy, a communication model has been created which could be naturally applied in many other situations in life.
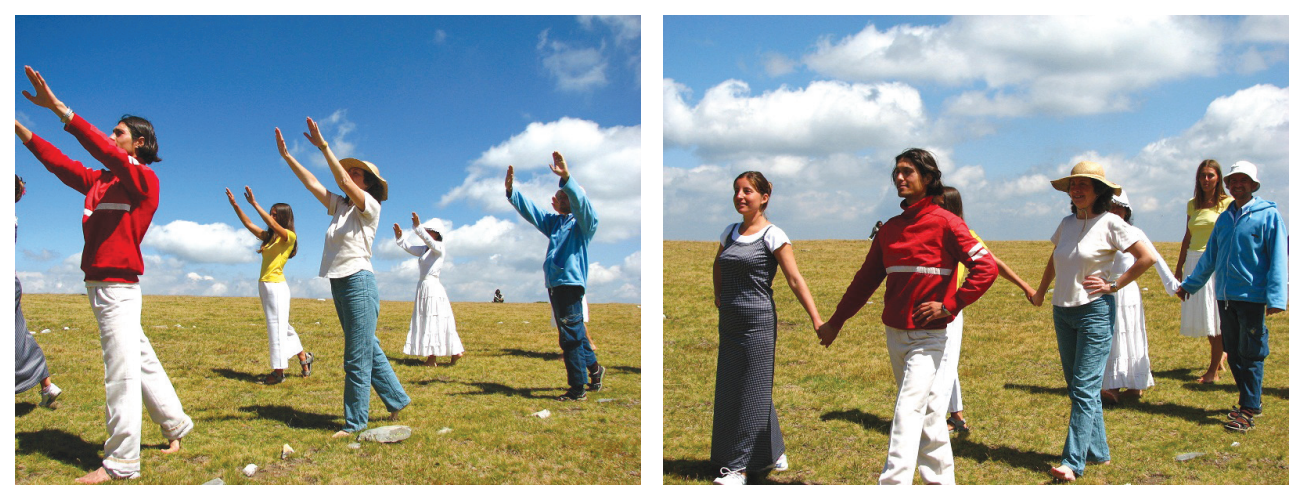

Figure 7. Moments of Paneurhythmy exercises

Source: Photos by Ludmila Chervencova.

\section{The general arpangement of participants}

All pairs participating in Paneurhythmy form one geometric figure specific for each part of Paneurhythmy (Figure 4). For example, in the first part, all pairs are arranged in one circle (or more) with one center. In the second part, groups of 6 pairs (12 persons) are formed, arranged in lines radiating from the centre and facing it, together with an external circle of pairs (Figure 8a). In the third part of Paneurhythmy, all participants are arranged in groups of 10, forming lines radiating from the center (with their left shoulder to it) (Figure 8b). Taking initial positions for the collectively shaped figures before the start of the performance, as well as preserving these shapes during the performance, requires special attention and the joint effort and cooperation of all participants to keep the general design of Paneurhythmy. This situation naturally promotes partner relations in the group, and with the regular practice of Paneurhythmy, it cultivates the skills and habits for successful cooperation.

The arrangements of the participants in the second (Sunrays) and third (Pentagram) parts of Paneurhythmy are visible in Figure 8. 

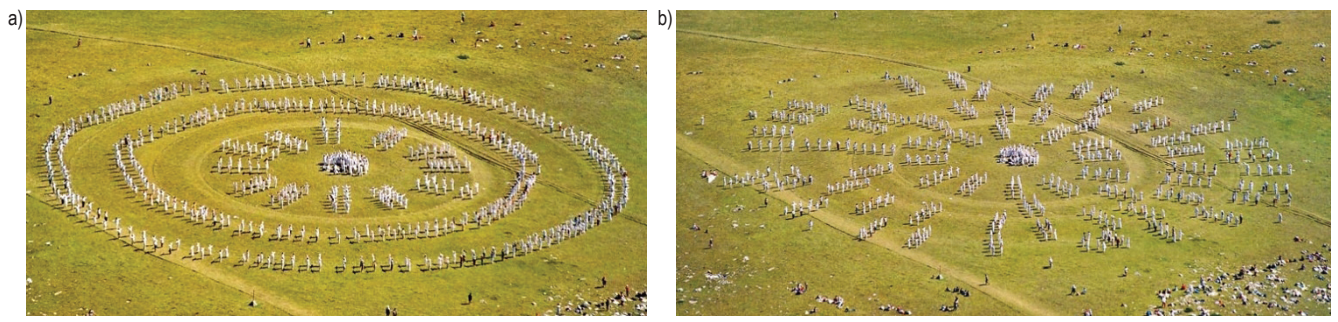

Figure 8. Photos of the largest Paneurhythmic performances in the world: Bulgaria, August 19-21, Rila Mountain Source: Photos by Zhsivko Stoilov.

\section{The type of music}

There is variety in the music of Paneurhythmy, but without any strong or dramatic notes in it, which might suggest anxiety, hostility or aggression. The tempo, tonality and other musical forms vary in the music for Paneurhythmy exercises, but a general a positive note is constantly present. In the language of music, it is an expression of peace and harmony.

\section{The lypics of the songs for Paneurhythmy}

Each performance of Paneurhythmy is accompanied by instrumental music and vocal singing (out loud, or silent) of the songs. In the beginner training course, they are sung or listened to during the exercises practiced during the course. The poetic lines of Paneurhythmy songs form a strong element in the general message of Paneurhythmy.

D. Ancheva (2003) made a detailed analysis of the Paneurhythmy song lyrics and found the complete set of lyrics contains 438 words (with repetitions it amounts to 2,536 words) with the majority of them related to the beauty of nature. The most frequently repeated topics in the text are: "There is light" and "Positive feelings and emotions" (their frequency respectively 273 and 270 words including repetitions). In the group of positive feelings and emotions, the most frequently repeated words are: "love" (52 times), "happiness" (46 times), "peace" (23 times), "sweet" (13 times), "I enjoy" and "gentle" (each one 11 times), "sweetness" and "grace" (each one 10 times) (Ancheva, 2003, 2007a). We believe that listening and singing these words in Paneurhythmy creates an environment which helps participants focus on the experience of these positive emotions. Thus, a positive atmosphere is created for friendly relations, a basic condition for a fruitful partnership.

Another aspect of the Paneurhythmy song lyrics we find important with reference to partnership, is the proportion of words related to the "Ego" and to the "group". Words related to the "Ego" are used 30 times in the songs, while words related to the "group" 132 times, a proportion of 1:4 approximately. Also, verbs expressing "I am doing something" are used with a frequency of 21, while those, expressing "we are doing something" with a frequency of 98 , again roughly a proportion of 1:4 (Ancheva, 2003). D. Ancheva has good reason to conclude that each person and their "Ego" are placed in the centre of the lyrics. However, personal "Ego" is expressed in words four times less often than social "Ego", in favor of the message "we are all together" (Ancheva, 2003). Consequently, the lyrics of the Paneurhythmy songs in a natural way help the participants realize they are not only individuals, but also partners in their pair and in the group. 
According to D. Ancheva (2007a), it is important to note that in the lyrics of the Paneurhythmy songs there are two imperative forms about human attitude to the world: rejoice with the world and help the world.

The meaning of Paneurhythmy is revealed through three messages of global empathy in the song lyrics a bright future for the whole of mankind; brotherhood and love among people; peace, freedom, beauty, happiness and love for all reasonable souls (Ancheva, 2007a).

\section{The philosophy of Paneurhythmy}

The basis of Paneurhythmy is a philosophy seeking to create in man qualities stimulating good human relations. Peter Deunov determines as most important the basic principles of Love, Wisdom and Truth, and the virtues ensuing from them - magnanimity, mercy, love, sweetness, gentleness, justice, peacemaking, good reason, bravery, mutual aid, generosity, brotherhood, patience, perseverance, etc. Most of these virtues are mentioned or described in the song lyrics of Paneurhythmy. In the training course of Paneurhythmy for children, focusing children's attention on some of these virtues in a manner suitable for their age, helps their better understanding and application in life. Adults practicing Paneurhythmy also listen/sing about those virtues in the song lyrics, and some of them read about them in the lectures of the author of Paneurhythmy. All that experience stimulates the desire of people studying and practicing Paneurhythmy to acquire these valuable qualities, fundamental for their good interpersonal and social relations.

\section{Acting out social poles}

The geometric figures, formed by groups in Paneurhythmy have special meaning, and their understanding becomes clear and more powerful during the performance of particular social roles in the group. We can give an example of understanding particular role situations in the group through Paneurhythmy in the performance of the third part called Pentagram. Participants are divided into groups of five pairs, each group symbolically represents one greater parson (one pentagram), whose components are related to particular virtues (Figure 9). According to the author of Paneurhythmy, the Pentagram, inserted into a circle, symbolizes man in the course of evolutionary development, each peak and side of the pentagram is related to a definite virtue: Love, Wisdom, Truth, Justice, and Virtue (Duno, 2008, p. 5). The five pairs in the pentagram change places five times, each pair goes through all positions including the position of "leader". When a certain pair is at the top, corresponding to the human "head", that is, to the virtue of "Truth", they take the role of "leader", responsible for the movement of the whole group. When the pair is situated at one of the other four peaks of the pentagram, it abides by the leading role of the pair in the place of "head", and acts according to their other role of following the "leader".

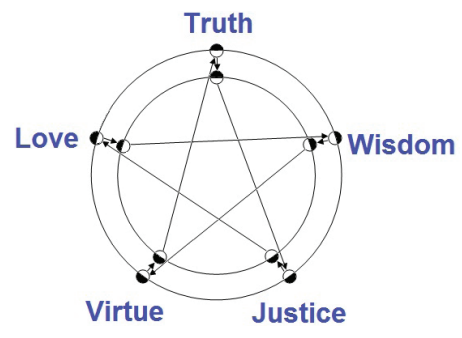

Figure 9. Group figures as part of the exercise "Pentagram" (the third part of Paneurhythmy) 


\section{Widening the range of awareness}

While performing Paneurhythmy, everyone should coordinate his/her own movements with the music, together with the movement in space of the other participants, who, in most cases, are also in motion. An experienced practitioner watches and coordinates his/her movements with those of the other participants on several levels (the pair, adjacent pairs, a small group, larger groups, etc.), taking appropriate actions. Performance of the most complex group geometric figures in Paneurhythmy requires that good practitioners synchronize their own movements with the music and with their partner, and to be aware of, to create, to keep or to go from one to other regular geometric figures while moving in space, participating in several different size groups which form these various figures. This is a higher level of coordination in groups which requires widening of the attention span, and practically trains skills for more complex group interactions.

\section{Discussion}

This article for the first time presents a detailed theoretical analysis, revealing more completely and clearly the potentials of Paneurhythmy to improve personal relations. In addition to that it provides available research data, showing that practicing Paneurhythmy improves partner skills and social functioning with children and adults.

Paneurhythmy resembles dancing very much and probably influences relationships in a similar way to that recorded in group dancing. There is research information on the social-cognitive aspects of dance-related forms of rhythmical full body movement (Sevdalis, Keller, 2011).

Dance is a form of physical activity to promote physical and mental health to some who are not otherwise active and may be a form of activity that is more acceptable than others in certain cases (Olvera, 2008). The same refers to Paneurhythmy. Our study (Chervencova, 2012) reveals significant improvements in the psychological state, physical indicators and the subjective health as a result of the participation in a Paneurhythmy course. Besides, for $29 \%$ of the participants that Paneurhythmy course was the first step of getting over the state of hypokinesia (Chervencova, 2013).

\section{Research with children trained in Paneurhythmy}

S. Mihalkova (2001) has found that one school year of initial training in Paneurhythmy exercises for children leads to a significant improvement of their concentration and attention span. This is considered to be due to the necessity to pay special attention to a number of dynamic elements while practising Paneurhythmy. Mihalkova (2001) points out that when performing Paneurhythmy, participants have to meet high requirements with reference to the characteristics of their attention:

concentration - participants should not distract their attention during the entire performance, they should synchronize their movements with the music; distribution - participants should be in constant connection with their partners, as well as, with the others in the circle, they should perform the separate exercises in synchronism with their partners; volume - participants should follow the general movement in the circle and keep the distance between the pairs, and the distance from the centre; switching over - they should follow the sequence of exercises and perform each one of them with the necessary movements and rhythm (Mihalkova, 2001). 
The author's practical experience as a lecturer and practitioner of Paneurhythmy shows that a Paneuthythmy performance requires attention and alertness to the many components, a large number of them connected with watchfulness and adequate interaction with other participants - the partner, adjacent pairs and participant groups of different size. That is why practicing Paneurhythmy develops habits and skills of awareness and attention to partner and group processes. Once acquired, these habits and skills are applicable not only in Paneurhythmy, but in many other areas of life, where one acts as a social being.

J. Zukauskas (1998) underlines that elementary school children often exhibit a lack of social skills that interferes with positive classroom interaction. On the other hand, a significant amount of TV models negatively foster anti-social and careless behavior (Zukauskas, 1998). In this situation, widening the pathways for teaching social skills is an important task. That is why it is important to study practices such as Paneurhythmy, which are accessible and can effectively develop children's social skills.

Grounded on the analysis of projection tests and thematic drawings, G. Kubratova (2003) points out that with 82 children (aged 9-11) having completed a three-year course of education in Paneurhythmy, there is a "stable trend to form inclinations to tolerance, cooperation and altruism in communication with others". V. Matanova and A. Yankova (2007b) found in their controlled study of Paneurhythmy training, based on the program "Health through movement in the open nature", that with 167 children (aged 5-7), the greatest changes due to Paneurhythmy practice are in the field of social contacts and social skills. The same authors have come to the conclusion that practicing Paneurhythmy at pre-school age helps to reveal children's potential abilities and enhances the process of socialization, based on their proper cognitive and emotional development.

The majority of teachers (82\%) of over 100 children participating in the program "Health through movement in the open nature", which includes Paneurhythmy training, share the opinion that as a result of the program, the children have become calmer and share more positive emotions, which has a beneficial influence on their interpersonal relations and on the whole process of their education and cooperation in class (Boyadjieva, Yankova, 2007). This shows that the participation of children in Paneurhythmy training increases their positive emotions, positive behavior and creates prosocial classroom environment. The sociometric status is an indicator of social competence. The sociometric status is not widely used, but it is the best measure of social skills (Cillessen, Bellmore, 2004). Matanova and Yankova (2007a) apply socio-metric methods in their study of interpersonal relations with 129 school pupils (in the 1-4 form), practicing Paneurhythmy (once per week) and 134 children of the same age who formed the control group. The results show that in the group of children practicing Paneurhythmy, there is a greater desire for cooperation and friendliness. Matanova and Yankova (2007a) note that the informal group organized for the Paneurhythmy practice had a positive influence on interpersonal relations at primary school age. This positive attitude is expressed mainly through a high level of solidarity and desire to help and support others. The authors point out: "the Bulgarian school system teaches children many things, but it does not teach them social skills, so any kind of influence in this direction should be supported" (Matanova, Yankova, 2007a).

\section{Research with adults}

Two studies involving adult subjects show improvements in the social sphere as a result of their participation in a Paneurhythmy training course. O. Anchev (2003) found that a six-month training in Paneurhythmy of 12 adults (aged 20-65) expanded their circle of social relations and helped them overcome social isolation. 
A study on health-related quality of life with 149 adults (74 trained in Paneurhythmy and 75 in a control group), confirms that the beginner training in Paneurhythmy significantly improves subjective health, the item "Social functioning" shows an increase of $18 \%$ compared to the initial results (Chervencova, 2013, p. 165).

Research studies on persons already practicing Paneurhythmy also show that they have noticed important changes in their relations and communication with others, which they believe are due to their Paneurhythmy practice. L. Chervencova (2004) published the results of an enquiry with 140 subjects (aged 47 on average) already practicing Paneurhythmy. The subjects of the enquiry reported various positive changes as a result of their Paneurhythmy practice to the moment of the enquiry. It is interesting to note that the most frequent changes refer to improving their relations - this has been noted by $83.6 \%$ of the subjects practicing Paneurhythmy (Chervencova, 2004).

Twenty-two teachers by profession (graduated or graduating special training as teachers in Paneurhythmy at the National Sports Academy) completed an enquiry with reference to the usefulness of Paneurhythmy for them personally. They noted the following positive changes in their relations with other people as a result of practicing Paneurhythmy: more patience, tolerance (noted by $55 \%$ of subjects in the enquiry); accepting others, forgiveness $(36 \%)$, widening the circle of acquaintances (31\%), responsiveness (31\%); improving personal relations $(27 \%)$ (Ancheva, 2007b).

\section{Conclusion}

Analysis of the components of Paneuthythmy reveals its great potential for the development of partnership skills and for the improvement of social functioning. In this respect, the most significant characteristics of Paneurhythmy are: group practice, the appropriate aim of the practice, the right music, common rhythm and synchronization of movements, specific distances between participants, typical characteristics and expressiveness of participant movements, Paneurhythmy philosophy, sharing space, suitable lyrics of Paneurhythmy songs, figures for the arrangement of participants, acting social roles, and broadening the range of awareness.When so many factors work together for the improvement of social contacts, it makes them easier to be improved. That is why better social skills are achieved through the practice of Paneurhythmy.

The last statement is confirmed by existing scientific studies on the subject to date, revealing that with children and adults, both the initial training and further practicing of Paneurhythmy leads to the improvement of interpersonal relations and social skills.

We hope that the present article will motivate scientists to do further research on the subject and many more pedagogues and people, interested in their personal development, will use Paneurhythmy as an effective practice for improvement in the sphere of social contacts.

\section{References}

Anchev, O. (2003). Study on the effects of Paneurhythmy training on the self-esteem enhancement. Second scientific conference for Paneurhythmy: Paneurhythmy: a system for the harmonious development of people and society - reports. Paneurhythmy Research and Application Institute, Sofia, 76-87 (in Bulgarian).

Ancheva, D. (2003). Quantitative analysis of the text of Paneurhythmy with a content analysis method, II Scientific Conference Paneurhythmy: a system for the harmonious development of people and society - reports. Sofia, Paneurhythmy Research and Application Institute, Sofia, 52-75 (in Bulgarian).

Ancheva, D. (2007a). Spiritual health and Paneurhythmy: a quality and quantity content analysis of the text. Paneurhythmy: a system for the harmonious development of people and society. Paneurhythmy Research and Application Institute, Sofia, 87-98 (in Bulgarian). 
Ancheva, D. (2007b). A specialization in Paneurhythmy: conditions, usefulness, opportunities. Paneurhythmy: a system for the harmonious development of people and society, Paneurhythmy Research and Application Institute, Sofia, 100-108 (in Bulgarian).

Bachev, M. (2015). Intuition and logic: a dialogue about the spiritual and philosophical worldview of Peter Deunov. First National Conference: Peter Deunov, The Master in the cultural space of Bulgaria, 21-37 (in Bulgarian).

Bachev, M. (2017). The triangle of existence. The philosophical ideas of young Peter Deunov. Zahari Stoyanov Publishers and the Bialo Bratstvo Publishers, Sofia (in Bulgarian).

Beinsa Douno (1938). Paneurhythmy, Sofia (in Bulgarian).

Beinsa Douno (2004). Paneurhythmy. Sofia: Bialo Bratstvo Publishers., Sofia, Retrieved from: http://www.panevritmia.info/images/ uploads/Paneurhythmy_2004_english.pdf (18.08.2019).

Boyadjieva, N., Yankova, A., Yacevich, V. (2007). Effects of Paneurhythmy on the psycho-emotional state and the state of anxiety among pupils from the first to the sixth grade. Included in: The Paneurhythmy as a system for harmonious development of the people and the society. Paneurhythmy Research and Application Institute, Sofia, 29-42 (in Bulgarian).

Boycheva, V., Donevska, N., Vancheva, T. (2001). Paneurhythmy as a system of education. The first scientific conference for Paneurhythmy: The Paneurhythmy as a system for harmonious development of the people and the society - reports. Sofia, 40 (in Bulgarian).

Cacioppo, J.T., Cacioppo, S. (2014). Social relationships and health: The toxic effects of perceived social isolation. Social and personality psychology compass, 8 (2), 58-72.

Chervencova, L. (2004). A survey about the psychophysical changes which occur by practicing Paneurhythmy. Included in: Sport, society, education, volume 9. Sofia, 166-178 (in Bulgarian).

Chervenckova, L. (2012). Investigation of Physical and Mental Influence of Paneurhythmy. Doctoral Dissertation, University: National sports academy "Vassil Levski" - Sofia, (in Bulgarian).

Chervencova, L. (2013). Paneurhythmy, health and wellness: a Bulgarian model of physical activity. St. KI. Ohridski University Press (in Bulgarian). Retrieved from: http://panevritmia.info/images/uploads/Panevritmia-zadrave-i-blagopoluchie-Chervenkova-2013. pdf (18.08.2019).

Chervencova, L.K., Ishev, N.N. (2015). Introducing Paneurhythmy-Group Exercises, Music, Poetry, Geometry and Nature Combined in Favor of Health. European Journal of Physical Education and Sport, 4, 172-180. Retrieved from: http://ejournal7.com/ journals_n/1453146328.pdf (19.08.2019).

Cillessen, A.H., Bellmore, A.D. (2002). Social skills and interpersonal perception in early and middle childhood. In: P.K. Smith, C.H. Hart (eds), Blackwell handbooks of developmental psychology. Blackwell handbook of childhood social development (pp. 355-374). Blackwell Publishing.

Cohen, S. (2004). Social relationships and health. American Psychologist, 59 (8), 676.

Constitution of the World Health Organization. In: World Health Organization: Basic documents. 45th ed. Geneva: World Health Organization; 2005.

Deunov, P. (2015). The Life and Teachings of Peter Deunov (edited by David Lorimer). Hay House Publishing.

Dyer, W. (2015). The Foreword in book Prophet for our Times: The Life and Teachings of Peter Deunov (edited by David Lorimer). Hay House Publishing.

Grusec, J.E., Davidov, M., Lundell, L. (2002). Prosocial and helping behavior. In: P.K. Smith, C.H. Hart (eds), Blackwell handbooks of developmental psychology. Blackwell handbook of childhood social development (pp. 15, 457-474). Blackwell Publishing.

Jung, C.G. (2014). Psychology of Eastern Religion. Lege Artis Publishing House, p. 108 (in Bulgarian).

Kraleva, M. (2001). The Master Peter Deunov His life and Teaching (Foreword by David Lorimer). Kibea Publishing Company.

Kubratova, G. (2003). The teaching of Paneurhythmy - a glimpse of humanistic education in the period of crisis of the family and the school education systemta. Paneurhythmy as a system for the harmonious development of man and society. Second Scientific Conference - reports, NSA "V. Levski" and The Association of Paneurhythmy. Sofia, 87-93 (in Bulgarian).

Ladd, G.W., Buhs, E.S., Troop, W. (2002). Children's interpersonal skills and relationships in school settings: Adaptive significance and implications for school-based prevention and intervention programs. In: P.K. Smith, C.H. Hart (eds), Blackwell handbooks of developmental psychology. Blackwell handbook of childhood social development (pp. 394-415). Blackwell Publishing.

Malti, T., Perren, S. (2011). Social competence. In: Roger J.R. Levesque, Encyclopedia of adolescence (pp. 332-340). Academic Press Elsevier Inc.

Matanova, V., Yankova, A. (2007a). The influence of education in paneurhythmy on the interpersonal relations in primary school age. Paneurhythmy as a system of harmonious development of man and society. IIPP - Sofia, 50-53 (in Bulgarian). 
Matanova, V., Yankova, A. (2007b). Effects of Paneurhythmy trainings on the emotional, cognitive and social functioning during the pre-school age. Included in: The Paneurhythmy as a system for harmonious development of the people and the society. Paneurhythmy Research and Application Institute, Sofia, 43-49 (in Bulgarian).

Michalkova, S. (2001). Study on the psychological change due to Paneurhythmy trainings. The first scientific conference for Paneurhythmy: The Paneurhythmy as a system for harmonious development of the people and the society - reports. Sofia, 78-83 (in Bulgarian).

Morris, A.S., Eisenberg, N., Houltberg, B.J. (2011). Adolescent moral development. In: Roger J.R. Levesque, Encyclopedia of adolescence (pp. 48-55). Elsevier Inc.

Naidenova, D. (2003). Paneurhythmy as music therapy. In: The Second scientific conference for Paneurhythmy - reports. Paneurhythmy Research and Application Institute, Sofia, 46-51 (in Bulgarian).

Olvera, A.E. (2008). Cultural dance and health: A review of the literature. American Journal of Health Education, 39 (6), 353-359.

Phillips-Silver, J, Athena, C., Aktipis, C., Bryant G. (2010). The ecology of entrainment: Foundations of coordinated rhythmic movement. Music Percept. September, 28 (1), 3-14.

Sevdalis, V., Keller, P.E. (2011). Captured by motion: Dance, action understanding, and social cognition. Brain and cognition, 77 (2), 231-236.

Smith, P.K., Hart, C.H. (eds) (2002). Blackwell handbook of childhood social development. Blackwell Publishers.

Umberson, D., Karas Montez, J. (2010). Social relationships and health: A flashpoint for health policy. Journal of Health and Social Behavior, 51 (1 suppl), 54-66.

Zukauskas, J.A. (1998). Improving Cooperative Behavior through the Use of Social Skills Instruction. An Action Research Project Submitted to the Graduate Faculty of the School of Education - Saint Xavier University, Chicago, Illinois.

Cite this article aS: Chervencova, L. (2020). Paneurhythmy Exercises for Developing Partnership and Social Skills. Central European Journal of Sport Sciences and Medicine, 3 (31), 17-32. DOI: 10.18276/cej.2020.3-02. 